\title{
Blockade of vascular ATP-sensitive potassium channels reduces the vasodilator response to ischaemia in humans
}

\author{
P.J . B ij Istra ${ }^{1}$, J . A . C .J . den A rend ${ }^{1}$, J . A . L utterman' ${ }^{1}$, F. G . M . R ussel ${ }^{2}$, Th. Thien ${ }^{1}$, P. Smits ${ }^{1,2}$ \\ ${ }^{1}$ D epartment of Internal M edicine, D ivision of $\mathrm{G}$ eneral Internal M edicine, U niversity $\mathrm{H}$ ospital Nijmegen, Nijmegen, \\ The $\mathrm{N}$ etherlands \\ ${ }^{2}$ D epartment of Pharmacology, U niversity of Nijmegen, Nijmegen, The N etherlands
}

Summary Experimental data show that ATP-sensitive potassium $\left(K_{A T P}\right)$ channels not only occur in pancreatic beta cells, but also in the cardiovascular system, where they mediate important cardioprotective mechanisms. Sulphonylurea derivatives can block the cardiovascular $\mathrm{K}_{\mathrm{ATP}}$ channels and may therefore interfere with these cardioprotective mechanisms. Therefore, it is of clinical importance to investigate whether sulphonylurea derivatives interact with vascular $\mathrm{K}_{\text {ATP }}$ channels in humans. U sing venous-occlusion strain-gauge plethysmography, we investigated whether ischaemia-induced reactive hyperaemia is reduced by the sulphonylurea derivative glibenclamide in 12 healthy male non-smoking volunteers. Forearm vasodilator responses to three periods of arterial occlusion (2,5 and $13 \mathrm{~min})$ during concomitant infusion of placebo into the brachial artery were compared with responses during concomitant intra-arterial infusion of glibenclamide $\left(0.33 \mu \mathrm{g} \cdot \mathrm{min}^{-1} \cdot \mathrm{dl}^{-1}\right)$. A control study $(n=6)$ showed that time itself did not change the vasodilator response to ischaemia.
G libenclamide significantly increased minimal vascular resistance (from $2.1 \pm 0.1$ to $2.3 \pm 0.2$ arbitrary units, Student's t-test: $p=0.01$ ), and reduced mean forearm blood flow (from $37.5 \pm 2.0$ to $35.4 \pm 2.0 \mathrm{ml}$. $\mathrm{min}^{-1} \cdot \mathrm{dl}^{-1}$ after 13 min occlusion, A NOVA with repeated measures: $p=0.006$ ) and flow debt repayment during the first reperfusion minute (A NOVA with repeated measures: $p=0.04$ ). In contrast, total flow debt repayment was not affected. Infusion of glibenclamide into the brachial artery resulted in local concentrations in the clinically relevant range, whereas the systemic concentration remained too low to elicit hypoglycaemic effects. O ur results suggest that therapeutic concentrations of glibenclamide induce a slight but significant reduction in the early and peak vasodilation during reactive hyperaemia. [D iabetologia (1996) 39: 1562-1568]

Keywords ATP-sensitive potassium channels, glibenclamide, reactive hyperaemia, ischaemia, forearm blood flow.
In 1983, Noma [1] was the first to describe that an outward potassium current increased significantly when guinea pig or rabbit cardiac muscle cells were subjected to hypoxia. This current was caused by the

Corresponding author: Professor P. Smits, D epartment of Pharmacology, U niversity of Nijmegen, P. O. Box 9101, NL-6500 $\mathrm{HB}$ Nijmegen, The N etherlands

A bbreviations: [A TP ], Intracellular A TP concentration; A U, arbitrary unit; dl, decilitre $=100 \mathrm{ml}$ (forearm volume); FBF, forearm blood flow; FV R, forearm vascular resistance; $K_{A T P}$ channel, ATP-sensitive potassium channel; L-NMMA, $N^{G}$. mono-methyl-L-arginine; NID D M, non-insulin-dependent diabetes mellitus. activation of potassium channels, which was independent of the intracellular $\mathrm{Ca}^{2+}$ concentration, but dependent on the intracellular concentration of adenosine-5'-triphosphate $\left([A T P]_{i}\right)$. These so-called A TPsensitive potassium ( $\left.K_{A T P}\right)$ channels were suggested to play a cardioprotective role during ischaemia. Later, $\mathrm{K}_{\mathrm{ATP}}$ channels were also found in skeletal muscle [2], smooth muscle [3] and pancreatic beta cells [4] from animals. In pancreatic beta cells the $K_{A T P}$ channels mediate insulin secretion [5] and are a target for sulphonylurea derivatives in the treatment of non-insulin-dependent diabetes mellitus (NIDD M) [6]. Sulphonylurea derivatives are highly specific in blocking pancreatic and cardiovascular $\mathrm{K}_{\text {ATP }}$ channels, and 
Table 1. Characteristics of the male non-smoking volunteers

\begin{tabular}{lll}
\hline & $\begin{array}{l}\text { Experimental } \\
\text { group } \\
\mathrm{n}=12\end{array}$ & $\begin{array}{l}\text { Control } \\
\text { group } \\
\mathrm{n}=6\end{array}$ \\
\hline A ge (years) & $28.2 \pm 7.7$ & $27.5 \pm 9.5$ \\
B ody mass index $\left(\mathrm{kg} / \mathrm{m}^{2}\right)$ & $22.3 \pm 2.0$ & $21.9 \pm 1.8$ \\
Systolic blood pressure $(\mathrm{mm} \mathrm{H} \mathrm{g})$ & $125 \pm 10$ & $127 \pm 6$ \\
D iastolic blood pressure $(\mathrm{mm} \mathrm{H} \mathrm{g})$ & $69 \pm 7$ & $74 \pm 9$ \\
H eart rate (beats/min) & $64 \pm 7$ & $60 \pm 7$ \\
\hline
\end{tabular}

$\mathrm{D}$ ata are means $\pm \mathrm{SD}$. Blood pressure was measured with a sphygmomanometer and heart rate after 5 min supine rest during the pre-investigation visit

therefore, have been widely used to study the role of $\mathrm{K}_{\mathrm{ATP}}$ channels in the regulation of insulin secretion, cardiac function and vascular tone. U nder ischaemic conditions the opening of cardiovascular $K_{A T P}$ channels triggers endogenous cardioprotective mechanisms which prevent a further ATP depletion by shortening of action potential with a decrease in contraction [7] and by vasodilation which results in an increased oxygen supply [8]. These mechanisms protect the myocardium against ischaemia and reperfusion damage and improve mechanical function during reperfusion [9]. The protective effects of ischaemic preconditioning have also been suggested to be mediated by opening of cardiovascular $\mathrm{K}_{\text {ATP }}$ channels [10, 11]. On the other hand, opening of $K_{A T P}$ channels may increase the incidence of arrhythmias [12, 13]. A s a result, in all kinds of animal models the cardiovascular consequences of blockade of $K_{A T P}$ channels by sulphonylurea derivatives are diverse, with extension of infarct size on the one hand [14] and reduction of fatal arrhythmias on the other [12, 13].

A II these effects of sulphonylurea derivatives have been demonstrated in animal models but, there are several arguments to suggest that they may also occur in humans [15]. U ntil now, data in humans on this important issue are very scarce. O ne of the first steps in this field must be to investigate whether a pathophysiological stimulus of the above-mentioned mechanism can be inhibited by therapeutic concentrations of sulphonylurea derivatives in man. Therefore, we now investigate in vivo in the human forearm whether ischaemia-induced vasodilation can be reduced by local therapeutic concentrations of the sulphonylurea derivative glibenclamide.

\section{Subjects and methods}

The study protocol was approved by the local ethics committee, and 18 healthy male non-smoking volunteers with a normal medical history, physical examination and blood pressure gave written, informed consent before entering the study. Their characteristics are listed in Table 1. They were instructed to abstain from caffeine-containing beverages and alcohol for at least $24 \mathrm{~h}$ before the experiment. Furthermore, they were asked to eat a light meal $2 \mathrm{~h}$ before the experiment was started and to abstain from further food intake until the end of the experiments. Forearm volume was measured by water displacement. E ach subject participated in only one experiment. A II experiments were performed in the afternoon with the subjects in the supine position in a quiet, temperature-controlled room $\left(22^{\circ} \mathrm{C}\right)$ to ensure that forearm blood flow (FBF) predominantly referred to forearm muscle perfusion [16, 17].

E ffect of glibenclamide on ischaemia-induced forearm vasodilation. In 12 subjects (experimental group) a cannula (A ngiocath, 20 gauge; D eseret $M$ edical Inc., B ecton Dickinson and Company, Sandy, U tah, U SA ) was inserted under local anaesthesia (xylocaine $2 \%$ ) into the left brachial artery for blood pressure measurement with a single line customer kit (V iggoSpectramed, No 992399A /14368; B ilthoven, The N etherlands) and a Hewlett Packard monitor (type 78353B; Hewlett Packard $\mathrm{G} \mathrm{mbH}$, Böblingen, G ermany), and for intra-arterial drug infusion with an automated syringe infusion pump (type STC521; Terumo Corporation, Tokyo, Japan). D rugs were infused at a volume rate of $100 \mu \mathrm{l} \cdot \mathrm{min}^{-1} \cdot \mathrm{dl}^{-1}$ of forearm volume. Forearm blood flow was measured by ECG -triggered venous occlusion mercury-in-silastic strain-gauge plethysmography (Hokanson EC4, D.E.; Hokanson Inc., Issaquah, Wash., U SA ). Four FBF curves per min were recorded. D uring all recordings of the FBF, the hand circulation was completely occluded by a wrist cuff inflated $100 \mathrm{mmHg}$ above the systolic blood pressure to ensure that measurements only referred to the forearm skeletal muscle vascular bed [18]. A neighbouring and a contralateral antecubital vein were cannulated for blood sampling. A rterial occlusion of the forearm was obtained by inflating an extra cuff on the left upper arm to $100 \mathrm{mmHg}$ above systolic blood pressure.

Figure 1 shows the course of the test. A fter an equilibration period of 35 min infusion of placebo (physiological saline) into the brachial artery was started. A fter $10 \mathrm{~min}$, baseline measurements of blood pressure, heart rate and FBF were taken during $5 \mathrm{~min}$ with concomitant intra-arterial infusion of placebo. Then, the $F B F$, in response to three increasing periods of forearm ischaemia (2,5 and $13 \mathrm{~min}$ ), was recorded during 3,5 and $5 \mathrm{~min}$ post-occlusive reperfusion time, respectively. D uring the last minute of the 13 min occlusion period subjects performed forearm exercise, inducing a maximal forearm vasodilation during reperfusion [19]. Infusions were interrupted $10 \mathrm{~s}$ after the start of arterial occlusion until $10 \mathrm{~s}$ before the end of occlusion.

A fter a subsequent equilibration of $40 \mathrm{~min}$ to allow parameters to return towards baseline levels, baseline values, were again recorded, during concomitant infusion of placebo. Then a second series of experiments with 2,5 and 13 min of forearm ischaemia was performed, but with concomitant intra-arterial infusion of glibenclamide $\left(0.33 \mu \mathrm{g} \cdot \mathrm{min}^{-1} \cdot \mathrm{dl}^{-1}\right)$ instead of placebo. This infusion rate leads to local forearm glibenclamide concentrations which are similar to systemic concentrations as reached daily during the treatment of NIDD M $[20,21]$. In this way the effect of therapeutic glibenclamide concentrations on the forearm vasodilator response to ischaemia was assessed locally.

Venous blood samples for insulin and C-peptide determinations were taken from the non-experimental arm before and at the end of the glibenclamide infusion and before the start of 5 and 13 min of arterial occlusion. B efore each occlusion period, venous blood samples from the experimental side were taken for the determination of local glibenclamide concentrations. A t all these sampling points, the plasma glucose concentration was measured immediately by a Glucocard glucose analyzer (type GT-1610; Kyoto Daiichi Kagaku Co., Kyoto, Japan). 


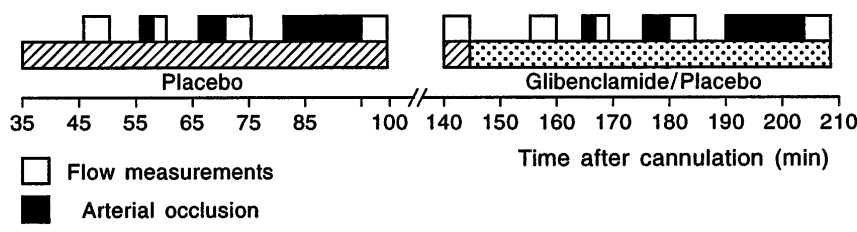

Fig. 1. Schematic view of the course of the protocol, indicating periods of arterial occlusion and flow measurements during concomitant infusion of placebo or glibenclamide

Because of the long half-life, high protein binding $[20,21]$ and possible incorporation of sulphonylurea derivatives in the plasma membrane [22], randomization of placebo and glibenclamide infusion was not possible because of carry-over effects.

Time-control study. In order to eliminate confounding factors such as time and the repeat of the procedure in the above-described protocol, a control study was performed.

In six subjects (control group) the above-described protocol was performed in the same manner, except that glibenclamide was not used in the second part. Therefore, placebo infusions and consequently an arterial line were not necessary. The repeat of the ischaemia-induced vasodilator responses was preceded by one baseline determination. Furthermore, no blood samples for insulin, C-peptide or glucose were taken. Instead, blood pressure was obtained with an automated recording device (D inamap, type 1846 SX/P Critikon, Tampa, Flori$\mathrm{da}, \mathrm{U} \mathrm{SA}$ ) every minute on the non-experimental arm.

Humoral parameters. For glibenclamide determinations, venous blood samples were collected in glass tubes without additives. A fter 20 min the blood was centrifuged at $3000 \mathrm{rev} / \mathrm{min}$ for $10 \mathrm{~min}$; serum was then frozen at $-20^{\circ} \mathrm{C}$. In these serum samples drug concentrations were determined at the laboratories of $\mathrm{H}$ oechst A G, Frankfurt, G ermany. G libenclamide was determined, using a validated specific radioimmunoassay (RIA ) [23]. The detection limit was $1-3 \mathrm{ng} / \mathrm{ml}$.

Insulin and $\mathrm{C}$-peptide concentrations were determined in venous blood samples collected in chilled glass tubes coated with lithium-heparin. The blood was centrifuged at $3000 \mathrm{rev} /$ min for $10 \mathrm{~min}$. Then plasma was frozen at $-20^{\circ} \mathrm{C}$. In these samples insulin and C-peptide were determined in our laboratories using specific RIA S. C-peptide was measured with a standard kit (D.P.C., L os A ngeles, Calif., USA ). In the insulin assay, standard and tracer insulin was prepared from monocomponent human insulin (N ovo, Z oeterwoude, The N etherlands).

Calculations. Forearm vascular resistance (FVR) was calculated as the quotient of mean arterial pressure and simultaneously measured FBF, and expressed as arbitrary units $(A U)$. B aseline values were averaged to one mean representative value. D uring each reperfusion period after an ischaemic stimulus, maximal FBF and minimal FVR, as well as the mean $F B F$ and FVR during the first reperfusion minute were determined. Flow debt was determined as the preocclusion baseline FB F multiplied by the duration of occlusion. Flow debt repayment was determined as the area under the FBF vs the time curve during reactive hyperaemia minus preocclusion baseline FBF times the duration of reactive hyperaemia. Percent flow debt repayment was calculated as flow debt repayment divided by flow debt multiplied by 100 [24]. A Iso, flow debt repayment during the first reperfusion minute was computed. Flow debt repayment is expressed as $\mathrm{ml}$ per $\mathrm{dl}$ of forearm volume.

\section{Statistical analysis}

To avoid multiple comparison and to investigate a shift of the stimulus response curves, within subject effects were statistically analysed by an analysis of variance (A NOVA) with repeated measures over all periods of ischaemia, and post-hoc paired Student's t-test were used to show after which stimuli inhibition was most pronounced. The SPSS PC +3.0 program (Statistical Package for Social Sciences) was used, and $p<0.05$ was considered statistically significant. Values presented are means \pm SE M , unless indicated otherwise.

\section{Results}

Intra-arterial recordings of baseline systolic and diastolic blood pressure averaged $115 \pm 13$ and $66 \pm$ $6 \mathrm{mmHg}$, respectively in the experimental group, and $119 \pm 6$ and $61 \pm 8 \mathrm{mmHg}$ in the control group. B aseline heart rate was $58 \pm 8$ and $58 \pm 10$ beats per min in the experimental and control group, respectively. D uring the experiments these parameters did not change.

In both groups the baseline FBFs did not significantly change throughout the protocols, and consequently the flow debts caused by the corresponding periods of arterial occlusion remained statistically unchanged.

Forearm vascular responses to ischaemia. The three increasing periods of ischaemia resulted in significant responses of all flow parameters, with more pronounced responses after longer occlusion times. FBF reached a maximal value of $41.9 \pm 2.3 \mathrm{ml} \cdot \mathrm{min}^{-1} \cdot \mathrm{dl}^{-1}$ after 13 min of occlusion (Table 2), and after 2 and 5 min of ischaemia a 10- to 15 -fold increase in baseline blood flow was reached. FVR reached a minimum value after $13 \mathrm{~min}$ ischaemia of $2.1 \pm 0.1 \mathrm{AU}$. A fter 2 and 5 min ischaemia, these FV R values were respectively $3.0 \pm 0.1$ and $2.5 \pm 0.2 \mathrm{AU}$ (Fig.2). D uring the first reperfusion min mean FBF, mean FVR and the flow debt repayment showed significant responses to ischaemia which increased with the occlusion time (Figs. 2 and 3). A Iso, total flow debt repayment was increased significantly with the three increasing periods of ischaemia (Table 2 ).

E ffect of glibenclamide on responses to ischaemia. Infusion of glibenclamide did not change baseline parameters. M inimal FV R in response to three increasing periods of forearm ischaemia was significantly increased by glibenclamide, with post hoc t-tests indicating significant increases in minimal FVR after 2 and $13 \mathrm{~min}$ forearm ischaemia (Fig.2). Similarly, maximal FBF in response to the ischaemic stimuli showed a trend to decrease from $41.9 \pm 2.3$ to $40.8 \pm 2.9 \mathrm{ml} \cdot \mathrm{dl}^{-1} \cdot \mathrm{min}^{-1}$ in the presence of glibenclamide (Table $2, p=0.07$ ). G libenclamide significantly decreased the mean FBF and increased the mean 
Table 2. $\mathrm{H}$ aemodynamic parameters at baseline and after ischaemic stimuli

\begin{tabular}{|c|c|c|c|c|}
\hline \multirow[t]{2}{*}{ A rterial occlusion } & \multicolumn{2}{|c|}{$\operatorname{MaxFBF}\left(\mathrm{ml} \cdot \mathrm{min}^{-1} \cdot \mathrm{dl}^{-1}\right)$} & \multicolumn{2}{|c|}{ Total flow debt repayment $\left(\mathrm{ml} \cdot \mathrm{dl}^{-1}\right)$} \\
\hline & $\begin{array}{l}\text { Control } \\
\text { Placebo }\end{array}$ & $\begin{array}{l}\text { Experimental } \\
\text { Placebo }\end{array}$ & $\begin{array}{l}\text { Control } \\
\text { Placebo }\end{array}$ & $\begin{array}{l}\text { Experimental } \\
\text { Placebo }\end{array}$ \\
\hline \multirow[t]{2}{*}{$\begin{array}{l}\text { Baseline } \\
2 \mathrm{~min} \\
5 \mathrm{~min} \\
13 \mathrm{~min} \\
\text { Baseline }\end{array}$} & $\begin{array}{l}2.6 \pm 0.6 \\
27.9 \pm 4.4 \\
35.7 \pm 4.6 \\
45.1 \pm 4.7\end{array}$ & $\begin{array}{l}2.1 \pm 0.2 \\
28.2 \pm 1.3 \\
33.9 \pm 2.7 \\
41.9 \pm 2.3 \\
1.9 \pm 0.2\end{array}$ & $\begin{array}{l}239 \pm 53 \\
845 \pm 119 \\
4178 \pm 474\end{array}$ & $\begin{array}{l}278 \pm 34 \\
770 \pm 69 \\
4081 \pm 225\end{array}$ \\
\hline & Placebo & G libenclamide & Placebo & Glibenclamide \\
\hline $\begin{array}{l}\text { Baseline } \\
2 \mathrm{~min} \\
5 \mathrm{~min} \\
13 \mathrm{~min}\end{array}$ & $\begin{array}{l}1.8 \pm 0.3 \\
28.4 \pm 2.9 \\
34.3 \pm 3.3 \\
47.7 \pm 3.4\end{array}$ & $\begin{array}{l}1.8 \pm 0.2 \\
25.8 \pm 1.3^{a} \\
31.8 \pm 1.3 \\
40.8 \pm 2.9\end{array}$ & $\begin{array}{l}241 \pm 62 \\
708 \pm 108 \\
4085 \pm 640\end{array}$ & $\begin{array}{l}224 \pm 33^{a} \\
627 \pm 66 \\
3896 \pm 274\end{array}$ \\
\hline$p$-value & 0.74 & 0.07 & 0.39 & 0.14 \\
\hline
\end{tabular}

$D$ ata are means \pm SE M. B aseline forearm blood flow (FBF), maximal $F B F$ and total flow debt repayment during the first reperfusion minute after arterial occlusion during concomitant infusion of placebo and during the repeat with placebo (con-

FVR during the first reperfusion minute (Fig.3). Post-hoc t-test showed a small but significant increase in mean FV R after 13 min ischaemia from $2.4 \pm 0.1$ to $2.6 \pm 0.1 \mathrm{AU}$ (Fig. 3, $p=0.02$ ). M oreover, flow debt repayment during the first reperfusion minute was significantly reduced by glibenclamide (Fig.4). Despite decreased mean flow, increased mean vascular resistance and decreased flow debt repayment during the first reperfusion minute, the total flow debt repayment remained statistically unchanged during concomitant infusion of glibenclamide as compared with placebo (Table 2). Post-hoc t-test showed that total flow debt repayment after 2 min arterial occlusion was significantly decreased by glibenclamide (Table 2, $p=0.03$ ). If expressed as percentage flow debt repayment, reactive hyperaemia showed a similar pattern as total flow debt repayment.

Time control study. During the control experiments the three increasing periods of ischaemia caused significant responses in all flow parameters comparable to the experimental group. These changes were not significantly influenced by the repeat of the procedure (Figs. 2-4 and Table 2).

H umoral parameters. In the experimental group, systemic insulin, $\mathrm{C}$-peptide and glucose concentrations remained stable and were not changed significantly throughout the experiments. Insulin ranged from $7.5 \pm 0.8$ to $8.1 \pm 1.0 \mathrm{mU} / \mathrm{l}$, C-peptide ranged from $0.38 \pm 0.04$ to $0.43 \pm 0.04 \mathrm{nmol} / \mathrm{l}$ and glucose ranged from $4.2 \pm 0.2$ to $4.5 \pm 0.1 \mathrm{mmol} / \mathrm{l}$. Local glibenclamide concentrations varied from $65 \pm 7$ to $53 \pm 5 \mathrm{ng} /$ $\mathrm{ml}$ during the test and remained within a therapeutic range, while systemic glibenclamide concentrations were maximally $11.6 \pm 1.2 \mathrm{ng} / \mathrm{ml}$ at the end of the experiment, and remained below the therapeutic range as demonstrated by unchanged insulin levels $[20,21]$. trol group) or glibenclamide (experimental group). Within subject analysis: $p$-values from repeated measures A NOVA over all ischaemic stimuli. ${ }^{\text {a }}$ Post-hoc paired t-test $p<0.05$ vs preceding corresponding value

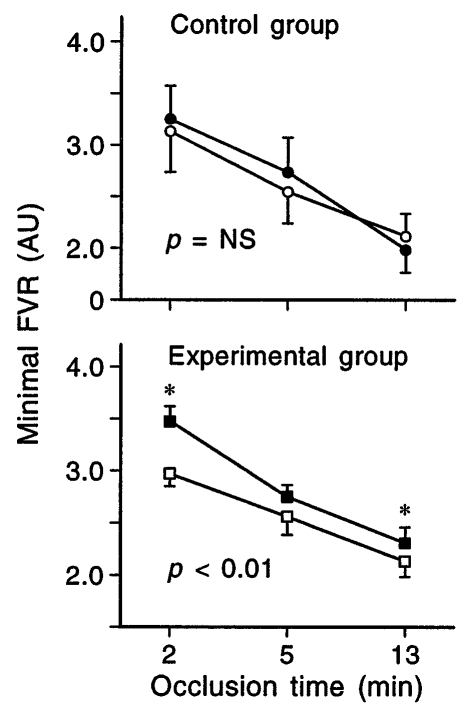

Fig. 2. M inimal forearm vascular resistance (FVR), after three periods of forearm ischaemia during concomitant infusion of placebo $(\bigcirc, \square)$ and during the repeat $(0, \square)$ with placebo in the control group $(n=6)$ or with glibenclamide in the experimental group $(n=12)$. p-values refer to ANOVA with repeated measures; ${ }^{*}$ post-hoc t-test $p<0.05$, mean \pm SE M

\section{Discussion}

Previous studies in animal models have shown that ischaemia-induced vasodilation could be reduced by sulphonylurea derivatives, which strongly argues for a role of vascular $K_{\text {ATP }}$ channels in this response [24, 25]. Sulphonylurea derivatives such as glibenclamide are widely used in the treatment of patients with NIDDM. Therefore, it is of great clinical importance to investigate whether therapeutic concentrations of sulphonylurea derivatives in humans can interact with vascular $\mathrm{K}_{\mathrm{ATP}}$ channel-mediated mechanisms. It has to be emphasized that experimental data derived 

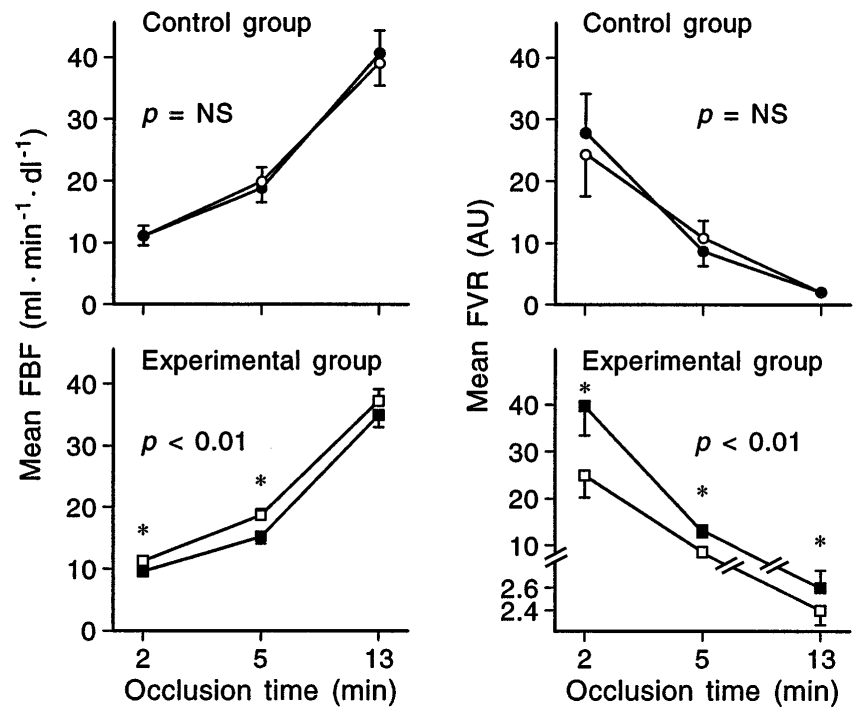

Fig. 3. M ean forearm blood flow (FBF, left panels) and mean vascular resistance (FVR, right panels) during the first re-perfusion minute after three periods of forearm ischaemia during concomitant infusion of placebo $(O, \square)$ and during the repeat $(\mathbf{O})$ with placebo in the control group $(n=6)$ or with glibenclamide in the experimental group $(n=12)$. $P$-values refer to A NOVA with repeated measures; ${ }^{*}$ post-hoc t-test $p<0.05$, mean \pm SE M

from animal studies are not necessarily relevant to the clinical situation of NIDDM patients because, in general, the concentrations of sulphonylurea derivatives used in animal models are much higher. M oreover, the high protein binding of sulphonylurea derivatives ( $>99 \%$ ) in humans considerably reduces the free fraction of the drug which is able to interact with the sulphonylurea receptor of the $K_{A T P}$ channel [21].

The present study suggests that therapeutic concentrations of glibenclamide significantly reduce the vasodilator responses to ischaemia in the forearm skeletal muscle vascular bed. This glibenclamide effect particularly concerns the peak vasodilation after ischaemia. The time-control study showed that repeating the procedure did not change the vasodilator response to ischaemia, and therefore, changes during the glibenclamide study could not be attributed to time effects or to the repeat of the procedure. The results were not biased by changes in systemic haemodynamic parameters (blood pressure, heart rate) since no significant changes occurred in these parameters during the experiments. O ur observations occurred at a glibenclamide plasma concentration of $\approx 60 \mathrm{ng} / \mathrm{ml}$, which is well within the clinically relevant range $[21,26]$. B ecause of the experimental model (intra-arterial infusions), these concentrations only occurred in the forearm vascular bed, and therefore we were able to avoid possible confounders such as increments in systemic insulin levels or hypoglycaemia. Consequently, the current observations show

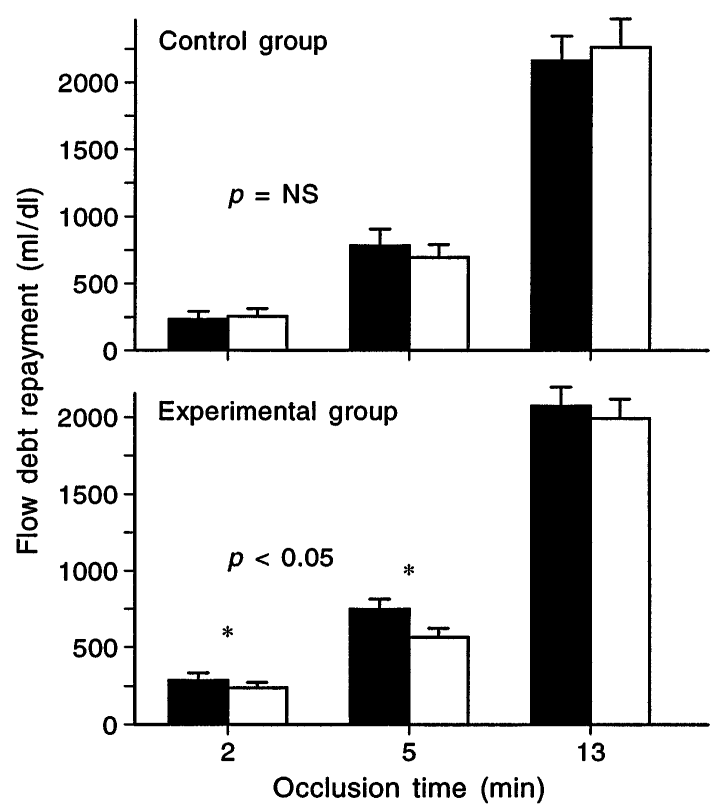

Fig. 4. Flow debt repayment during the first re-perfusion minute after three periods of forearm ischaemia during concomitant infusion of placebo ( $\square$ ) and during the repeat $(\square)$ with placebo in the control group $(n=6)$ or with glibenclamide in the experimental group $(n=12)$. p-values refer to A NOVA with repeated measures; "post-hoc t-test $p<0.05$, mean \pm SE M

that the relatively low concentrations of glibenclamide, which are likely to occur during the treatment of NIDDM, do slightly but significantly reduce the peak vasodilation after ischaemia suggesting an interaction with vascular $\mathrm{K}_{\mathrm{ATP}}$ channels. R ecently, Kosmas et al. [27] were the first to publish on this issue, but they reported on the effects of oral ingestion of $10 \mathrm{mg}$ of glibenclamide on the baseline and reactive hyperaemic blood flow in the calf of healthy volunteers. In contrast to our present observations, their results may have been seriously confounded by hyperinsulinaemia, hypoglycaemia, and subsequent stimulation of the sympathetic nervous system.

In this study, we evaluated three different ischaemic stimuli: 2, 5 and 13 min of arterial occlusion. Pedrinelli and colleagues [19] showed that the 13 min occlusion of the brachial artery with forearm exercise in the last minute, results in a maximal forearm vasodilation during reperfusion. Interestingly, glibenclamide not only reduced the vasodilator response to this maximal stimulus, but also affected the responses to the mild ischaemic stimuli. In general, the fall in intracellular ATP-concentration is considered to be the main trigger for the activation of $\mathrm{K}_{\text {ATP }}$ channels during ischaemia. H owever, magnetic resonance spectroscopy recordings on skeletal muscle during ischaemia in humans do not show evidence for a fall in these ATP-concentrations after these short periods of ischaemia [28]. A pparently, other mechanisms may have contributed to the activation of $K_{A T P}$ channels as reviewed previously [15], 
including localized decreases of A TP-concentration in a submembranous compartment of the cell [29, 30], endothelial release of a hyperpolarizing factor (endothelium derived hyperpolarising factor) [31], an increase in the intracellular concentration of adenosine-5'-diphosphate [32], an increase in interstitial concentrations of the A TP-degradation product adenosine [33], and alterations in concentrations of $\mathrm{M} \mathrm{g}^{2+}$ [34] or $\mathrm{pH}$ [35].

In contrast to short-term parameters, total flow debt repayment after arterial occlusion was not significantly inhibited by glibenclamide (Table 2). Indeed, several reports have suggested that only the initial cellular potassium efflux after ischaemia is mediated by activation of $K_{A T P}$ channels $[36,37]$. The delayed vasodilator response to ischaemia seems predominantly to be mediated by other mechanisms, including the endothelial release of endothelium-derived nitric oxide [38] and prostaglandins [39, 40]. This may explain why total flow debt repayment can be inhibited by $N^{G}$-monomethyl-L-arginine (a specific inhibitor of nitric oxide-synthase) [38] or by ibuprofen (a prostaglandin synthase inhibitor) [39], but not by the $\mathrm{K}_{\mathrm{ATP}}$ channel blocker glibenclamide. Interestingly, some animal studies have shown a significant reduction of total flow debt repayment by glibenclamide $[1,41]$. However, it has to be emphasized that these experiments were performed in the coronary circulation of animals, and with the use of high glibenclamide concentrations. M oreover, in such experiments glibenclamide has been shown to reduce basal coronary blood flow [37, 42]. In contrast, our experiments were performed in the human forearm vascular bed with relatively low glibenclamide concentrations. A ctually, the lower density of sulphonylurea receptors in the skeletal muscle vascular bed, as compared with the coronary circulation or with other ischaemia-sensitive tissues, may explain the aforementioned differences in results $[43,44]$. This, in return, may argue for more severe effects of blockade of $K_{A T P}$ channels in the heart than in the forearm.

The current human in vivo observations show that therapeutic glibenclamide concentrations affect the reactive hyperaemic response in the forearm vascular bed, suggesting a blockade of vascular $K_{A T P}$ channels. If this glibenclamide effect also holds for the myocardial $K_{A T P}$ channels, it may have important effects on the outcome of ischaemic events in diabetic patients on sulphonylurea therapy. Some epidemiological studies have shown evidence of a higher cardiovascular mortality or morbidity in diabetic patients on sulphonylurea therapy as compared with other therapies [45-47]. H owever, the methodological basis of those studies has been criticized, and other investigators were not able to reproduce the harmful effects of sulphonylurea derivatives [48-50]. I t is obvious that clinical trials with well-defined end points (infarct size, arrhythmias) are necessary to elucidate the clinical consequences of cardiovascular $\mathrm{K}_{\text {ATP }}$ channel blockade by sulphonylurea during the treatment of NIDDM.

In summary, our results show that blockade of vascular $\mathrm{K}_{\mathrm{ATP}}$ channels by therapeutic concentrations of glibenclamide induce a slight, but significant, reduction in the vasodilator response to ischaemia in humans. This observation may be of relevance in sulphonylurea-treated diabetic patients who suffer from ischaemic incidents.

A cknowledgements. This study was supported by a grant from the "Diabetes Fonds Nederland", grant nr: 93.101, and by $\mathrm{H}$ oechst $\mathrm{H}$ olland N. V.

\section{References}

1. Noma A (1983) A TP-regulated $\mathrm{K}^{+}$channels in cardiac muscle. N ature 305: 147-148

2. Spruce A E , Standen NB, Stanfield PR (1985) Voltage-dependent ATP-sensitive potassium channels of skeletal muscle membrane. Nature 316: 736-738

3. Standen N B, Q uayle J M , D avis NW, Brayden J E , H uang Y, Nelson M T (1989) Hyperpolarizing vasodilators activate A TP-sensitive $\mathrm{K}^{+}$channels in arterial smooth muscle. Science 245: 177-180

4. Cook DL, Hales CN (1984) Intracellular ATP directly blocks $\mathrm{K}^{+}$channels in pancreatic B-cells. Nature 311: 271-273

5. A shcroft FM, R orsman P (1990) A TP-sensitive K + channels: a link between $B$-cell metabolism and insulin secretion. B iochem Soc Trans 18: 109-111

6. Petit P, Loubatieres Mariani M M (1992) Potassium channels of the insulin-secreting $B$ cell. Fundam Clin Pharmacol 6: 123-134

7. Nichols CG, R ipoll C, Lederer WJ (1991) A TP-sensitive potassium channel modulation of the guinea pig ventricular action potential and contraction. Circ R es 68: 280-287

8. B rayden JE (1991) Hyperpolarization and relaxation of resistance arteries in response to adenosine diphosphate. Distribution and mechanism of action. Circ R es 69: 14151420

9. Cole W C, M CPherson CD, Sontag D (1991) A TP-regulated $\mathrm{K}+$ channels protect the myocardium against ischaemia/reperfusion damage. Circ R es 69: 571-581

10. Gross G J, A uchampach JA (1992) B lockade of A TP-sensitive potassium channels prevents myocardial preconditioning in dogs. Circ R es 70: 223-233

11. G ross G J, A uchampach JA (1992) R ole of A TP dependent potassium channels in myocardial ischaemia. Cardiovasc R es 26: 1011-1016

12. Billman GE, A vendano CE, Halliwill JR, Burroughs J M (1993) The effects of the A TP-dependent potassium channel antagonist, glyburide, on coronary blood flow and susceptibility to ventricular fibrillation in unanesthesised dogs. J Cardiovasc Pharmacol 21: 197-204

13. Sanguinetti M C (1992) Modulation of potassium channels by antiarrhythmic and antihypertensive drugs. H ypertension 19: 228-236

14. Thornton JD, Thornton CS, Sterling DL, Downey J M (1993) Blockade of A TP-sensitive potassium channels increases infarct size but does not prevent preconditioning in rabbit hearts. Circ $R$ es 72: 44-49 
15. Smits P, Thien Th (1995) Cardiovascular effects of sulphonylurea derivatives. Implications for the treatment of NIDD M ? D iabetologia 38: 116-121

16. Whitney RJ (1953) The measurement of volume changes in human limbs. J Physiol (Camb) 121: 1-27

17. Elia M , Kurpad A (1993) What is the blood flow to resting human muscle? Clin Sci 84: 559-563

18. L enders J W, Janssen G J, Smits P, Thien Th (1991) R ole of the wrist cuff in forearm plethysmography. Clin Sci 80: 413-417

19. Pedrinelli R, Taddei S, Spessot M, Salvetti A (1987) Maximal post-ischaemic forearm vasodilation in human hypertension: a re-assessment of the method. J Hypertens 5 [Suppl 5]: S431-S433

20. Coppack SW, Lant A F, M clntosh CS, Rodgers A V (1990) Pharmacokinetic and pharmacodynamic studies of glibenclamide in non-insulin-dependent diabetes mellitus. $\mathrm{Br}$ J Clin Pharmacol 29: 673-684

21. R upp v W, Christ O, Heptner W (1969) R esorption, A usscheidung und $\mathrm{M}$ etabolis-mus nach intravenoser und oraler Gabe von H B 419-14C an M enschen. A rzneim Forsch 19: 1428-1434

22. Niki I, Nicks JL, A shcroft SJ (1990) The beta-cell glibenclamide receptor is an A D P-binding protein. B iochem J 268: 713-718

23. U ihlein M, Sistovaris N (1982) High-performance liquid column and thin-layer chromatographic determination of human serum glibenclamide at therapeutic levels. J Chromatogr 227: 93-101

24. A versano T, O uyang P, Silverman H (1991) B lockade of the A TP-sensitive potassium channel modulates reactive hyperemia in the canine coronary circulation. Circ R es 69: 618622

25. D aut J, M aier Rudolph W, von B eckerath N, M ehrke G, Gunther K, Goedel Meinen L (1990) Hypoxic dilation of coronary arteries is mediated by A TP-sensitive potassium channels. Science 247: 1341-1344

26. M atsuda A, K uzuya T, Sugita Y, K awashima K (1983) Plasma levels of glibenclamide in diabetic patients during its routine clinical administration determined by a specific radioimmunoassay. H orm M etabol R es 15: 425-428

27. Kosmas EN, L evy RD, H ussain SNA (1994) A cute effects of glyburide on the regulation of peripheral blood flow in normal humans. E ur J Pharmacol 274: 193-199

28. Kemp GJ, Thompson CH, Barnes PR, R adda GK (1994) Comparisons of A TP turnover in human muscle during ischaemic and aerobic exercise using 31P magnetic resonance spectroscopy. M agn R eson M ed 31: 248-258

29. O pie LH (1993) M odulation of ischaemia by regulation of the A TP-sensitive potassium channel. Cardiovasc D rugs Ther 7 [Suppl 3]:507-513

30. Weiss J N, Lamp ST (1989) Cardiac ATP-sensitive $\mathrm{K}^{+}$ channels. E vidence for preferential regulation by glycolysis. J Gen Physiol 94: 911-935

31. Komori K, Vanhoutte PM (1990) Endothelium-derived hyperpolarizing factor. B lood Vessels 27: 238-245

32. Pfrunder D, A nghelescu I, K reye VA (1993) Intracellular ADP activates ATP-sensitive $\mathrm{K}^{+}$channels in vascular smooth muscle cells of the guinea pig portal vein. Pflugers A rch 423: 149-151

33. Nakhostine N, Lamontagne D (1993) A denosine contributes to hypoxia-induced vasodilation through A TP-sensitiveK + channel activation. A mJ Physiol 265: H 1289-H 1293

34. L ee K, O zanne SE, H ales CN, A shford M L (1994) M g ${ }^{(2+}$ )dependent inhibition of $K_{A T P}$ by sulphonylureas in CR I-G 1 insulin-secreting cells. Br J Pharmacol 111: 632-640

35. Davies N W (1990) M odulation of A TP-sensitive K + channels in skeletal muscle by intracellular protons. N ature 343: 375-377

36. Weiss J N, Venkatesh N, Lamp ST (1992) A TP-sensitive $\mathrm{K}^{+}$channels and cellular $\mathrm{K}+$ loss in hypoxic and ischaemic mammalian ventricle. J Physiol 447: 649-673

37. Wilde A A , E scande D, Schumacher CA et al. (1990) Potassium accumulation in the globally ischaemic mammalian heart. A role for the ATP-sensitive potassium channel. Circ R es 67: 835-843

38. Tagawa T, Imaizumi T, E ndo T, Shiramoto $M, H$ arasawa $Y$, Takeshita A (1994) R ole of nitric oxide in reactive hyperemia in human forearm vessels. Circulation 90: 2285-2290

39. Carlsson I, Wennmalm A (1983) Effect of different prostaglandin synthesis inhibitors on post-occlusive blood flow in human forearm. Prostaglandins 26: 241-252

40. Carlsson I, Sollevi A, Wennmalm A (1987) The role of myogenic relaxation, adenosine and prostaglandins in human forearm reactive hyperaemia. J Physiol 389: 147-161

41. L eipert B, Becker B F, G erlach E (1992) D ifferent endothelial mechanisms involved in coronary responses to known vasodilators. A m J Physiol 262:H 1676-H 1683

42. Samaha FF, H eineman FW, Ince C, F leming J, B alaban R S (1992) A TP-sensitive potassium channel is essential to maintain basal coronary vascular tone in vivo. A $m$ J Physiol 262:C 1220-C1227

43. A shcroft SJ, A shcroft FM (1992) The sulfonylurea receptor. B iochim B iophys A cta 1175: 45-59

44. A shcroft SJ, A shcroft FM (1990) Properties and functions of A TP-sensitive K -channels. Cell Signal 2: 197-214

45. U niversity G roup D iabetes Program (1970) A study of the effects of hypoglycemic agents on vascular complications in patients with adult-onset diabetes mellitus: II.M ortality results. D iabetes 19[Suppl 2]:785-830

46. Soler NG, B ennet M A , L amb P, Pentecost B L, FitzG erald M G, M alins J M (1974) Coronary care for myocardial infarction in diabetics. $L$ ancet I ( 856):475-477

47. K limt CR, Canner PL, Jacobs D R, Tominaga S, the Coronary D rug Project R esearch G roup (1977) The prognostic importance of plasma glucose levels and of the use of oral hypoglycemic drugs after myocardial infarction. Diabetes 26: 453-465

48. K een $\mathrm{H}$ (1971) Factors influencing the progress of atherosclerosis in the diabetic. A cta D iabet $L$ at 8[Suppl 1]:444-456

49. Paasikivi J, Wahlberg F (1971) Preventive tolbutamide treatment and arterial disease in mild hyperglycaemia. Diabetologia 7: 323-327

50. G ilbert J P (1975) R eport of the committee for the assessment of biometric aspects of controlled trials of hypoglycemic agents. J A M A 231: 583-608 